\title{
Seismic Response Study of Tunnels Running underneath a Subway Station in Parallel
}

\author{
Fuxue Sun, ${ }^{1}$ Guo-bo Wang $\mathbb{D}^{1},{ }^{1}$ Xiang-jun Peng, ${ }^{2}$ Zhou-zhou Jin, ${ }^{1}$ Xiao-chun Li, ${ }^{3}$ \\ and Jie-lin Zhao $\mathbb{D}^{2}$ \\ ${ }^{1}$ Department of Wenzhou University, College of Civil Engineering and Architecture, Wenzhou, China \\ ${ }^{2}$ Department of Wuhan University of Technology, Hubei Key Laboratory of Roadway, Wuhan, China \\ ${ }^{3}$ Department of Shanghai Tunnel Engineering Co., Ltd., Shanghai, China
}

Correspondence should be addressed to Guo-bo Wang; wgb16790604@126.com

Received 20 March 2020; Revised 2 June 2020; Accepted 20 June 2020; Published 27 July 2020

Academic Editor: Xiaonong Guo

Copyright (C) 2020 Fuxue Sun et al. This is an open access article distributed under the Creative Commons Attribution License, which permits unrestricted use, distribution, and reproduction in any medium, provided the original work is properly cited.

A tunnel passing below a metro station is taken as the object of our study, and a two-dimensional plane model is established to study the effects of their dynamic interaction to seismic excitation. Comparative analysis is used to obtain the influence law between the underground structures and on the soil. The results show that (1) the influence of the underground structure on the soil response is related to structure depth. The range of influence of the station structure on the surface is approximately five times the width of the station, and the surface response is obviously significant within this range. (2) The existence of the tunnel is conducive to reducing the acceleration of the column in the station. It increases the displacement difference between the stations, but the impact on the internal force of the station is not significant. (3) The influence of the station on the dynamic response of the tunnel is consistent with regard to tunnel acceleration, difference in displacement between the top and bottom of the tunnel, and internal force. The presence of the station will reduce the dynamic response of the tunnel.

\section{Introduction}

With increased development and utilization of urban underground space and the expansion and transformation of existing underground structures, underground engineering structures inevitably appear to pass each other at close distances, and cross-shaped and $X$-shaped traverse have emerged. As underground structures play an important role in the daily operation of the city, it is very critical to study the seismic performance of closed underground tunneling structures. Because an underground structure is buried in the soil, it is bound by the surrounding soil during an earthquake. The earthquake resistance mechanism of an underground structure is inevitably different from that of a surface structure: the seismic response of the surface structure is mainly controlled by the inertial force, whereas that of the underground structure is affected by the surrounding soil and mainly controlled by soil deformation. It is generally believed that the seismic performance of underground structures is superior to that of surface structures; therefore, the seismic problems of underground structures are often ignored. However, numerous underground structures have been seriously damaged in a series of large earthquakes around the world in the recent years. For example, the destruction of subway stations and tunnels caused by the Hanshin earthquake and Wenchuan earthquake indicates that underground structures are not absolutely safe, and their seismic performance needs to be studied [1-3].

Presently, there are many research studies on seismic resistance of underground structures, which have yielded constructive results. In terms of theoretical research, Lee and Trifunac [4] studied the dynamic response of tunnels during the early stage of an earthquake. The analytical solution of the tunnel dynamic response during an earthquake was derived through theoretical analysis and reasonable assumptions. In addition, the effects of soil-structure stiffness and tunnel depth on the dynamic response of the tunnel were analyzed. Bourouaiah et al. [5] revealed that soil properties have a great impact on soil-structure interactions, 
and the behavior at the interface between the soil and the structure depends directly on the soil properties, but the horizontal and vertical directions are affected differently. In terms of numerical simulation, Anastasopoulos et al. [6] simulated the immersed tunnel segment joints with nonlinear superelastic elements and studied the seismic response law of multisegment long-span tunnels under nonuniform seismic excitation. The analysis considered that the tunnel joint can effectively "absorb" a part of the deformation, and increasing the thickness of the joint gasket or reducing the length of the joint makes the structure more resistant to earthquakes. Pitilakis and Tsinidis [7] and Pitilakis et al. [8] analyzed the deformation behavior of rectangular underground structures during nonuniform earthquakes and pointed out that the special characteristics of underground structures make their seismic performance different from that of aboveground structures. Maugeri et al. [9] studied the performance of the shallow tunnel lining under seismic loading through numerical simulation and metaheuristic techniques. The results showed that genetic algorithm can be used to evaluate the safety performance of the tunnel lining. Wen et al. [10] studied the plastic failure behavior of tunnels, and the results showed that the plastic failure of the upper cross section of the tunnel was more serious than that of the lower part. Presently, there are numerous research results on the lateral response of structures, and the longitudinal response of the structure is gradually receiving attention. Park et al. [11] performed pseudostatic three-dimensional finite element analysis of tunnel structures under the action of spatially varied ground motion. It was pointed out that the spatial ground motion will cause the tunnel to bend longitudinally and increase the longitudinal axial force of the tunnel. Chen et al. [12] carried out a model shaking table test of the tunnel structure. It was considered that the dynamic response of the tunnel structure under nonuniform seismic excitation was greater than that under uniform seismic excitation. Therefore, the spatial effect of seismic excitation should be considered in the tunnel design. A related test by Cilingir and Gopal Madabhushi [13, 14] found that the ground motion response of the tunnel structure depends on the peak acceleration of the seismic excitation, and the change in the buried depth does not affect the tunnel deformation mode; it mainly affects the tunnel acceleration and internal force. Moghadam and Baziar [15] studied the mode of influence of the tunnel on the ground dynamic response during an earthquake by using a combination of the shaking table test and numerical simulation. Hashash et al. [16] reviewed the current state of seismic analysis and design of underground structures, introduced the quantitative methods used by engineers to assess the seismic action on underground structures, and expounded the deterministic and probabilistic methods for seismic hazard analysis. Numerical analysis tools such as the finite element method or finite difference method are used to analyze the dynamic soil-structure interactions. The effects of the relative structural flexibility of soil on the structural deformation and other properties have been studied, and calculation methods have been proposed. Abate and Massimino [17] studied the effects of the tunnel depth, aboveground structure position, and input seismic waveform on the dynamic interaction of the tunnel-soil-ground structure system based on an actual case in Italy. The system was fully coupled and analyzed. Thirty different recorded accelerations were analyzed based on the time domain, frequency domain, seismic bending moment, and axial force on the tunnel lining.

Most of the existing related researches are directed to a single simple structure, such as a rectangular subway station or circle tunnel, and the influencing factors (seismic excitation amplitude and type, structural depth, structure size, and form) are relatively simple. There is a lack of research on multiple structural systems, such as tunnels crossing each other, subway stations crossing each other, and tunnels crossing subway stations from below or above. In addition, their interactions have not been sufficiently explored, and it is difficult to draw a systematic general law. The purpose of this paper is to establish a two-dimensional model to study the influence of different positional relationships between structures on the dynamic response of the structures in a traversing system and draw some general conclusions.

\section{Calculation Models}

There are many engineering cases of tunnels passing through subway stations in China. In order to reflect the generality, the research object of this article is not a specific engineering case, but an abstract general model from actual projects, which can obtain a general research result.

2.1. Calculation Range and Boundary Conditions. This paper studies the seismic response of tunnels running underneath a metro station structure. Because the tunnel and station structure are not changed along the longitudinal section, the problem can be simplified to a plane problem under the action of seismic waves perpendicular to the longitudinal direction of the tunnel and the metro station. Therefore, this paper establishes a two-dimensional plane model, and the calculation software used is ABAQUS.

The subway station is a two-story and two-span frame structure with a cross-sectional dimension of $24 \mathrm{~m} \times 14 \mathrm{~m}$, side wall width of $0.8 \mathrm{~m}$, center pillar width of $0.6 \mathrm{~m}$, top plate and bottom plates are both of $0.9 \mathrm{~m}$, and a middle floor slab thickness of $0.4 \mathrm{~m}$. The outer diameter of the tunnel is $6 \mathrm{~m}$, inner diameter is $5.3 \mathrm{~m}$, thickness of the lining is $0.35 \mathrm{~m}$, and the distance between the centers of the two tunnels is considered as $0.5 \mathrm{D}, \mathrm{D}, 2 \mathrm{D}$, and $3 \mathrm{D}$ ( $\mathrm{D}$ is tunnel diameter). The tunnel depth is $17.5 \mathrm{~m}$ or $26 \mathrm{~m}$, corresponding to shallow buried tunnels and deep buried tunnels, respectively. Based on existing research results [18], the width of the calculation model is 7 times the width of the station (three times the width of each station on the left and right sides), that is, $168 \mathrm{~m}$, and the depth is $50 \mathrm{~m}$ to the bedrock surface.

The established station and tunnel models are shown in Figure 1. The finite element model includes a free-field model, spatially varying ground motion soil-station model, soil-double hole tunnel model, and soil-tunnel-station model, as shown in Figure 2. 


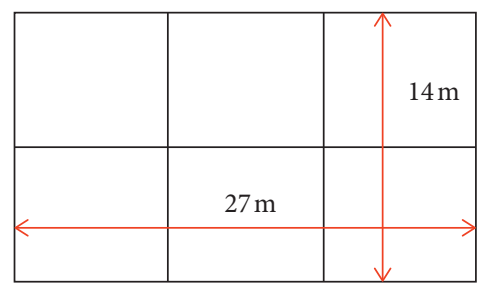

(a)

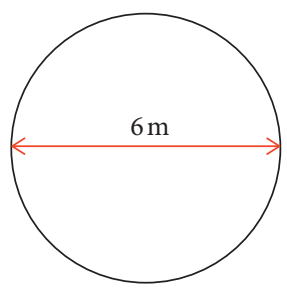

(b)

FIgURe 1: Underground structure model. (a) Station structure. (b) Tunnel structure.

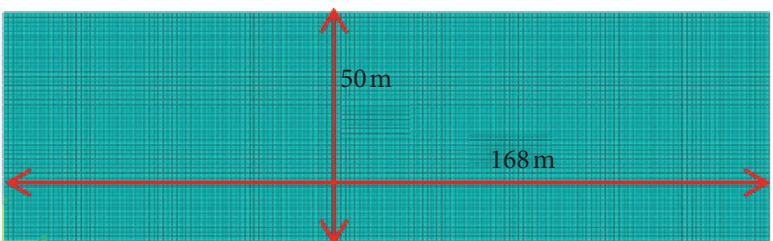

(a)

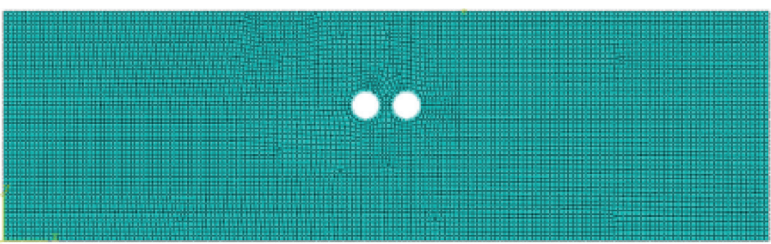

(c)

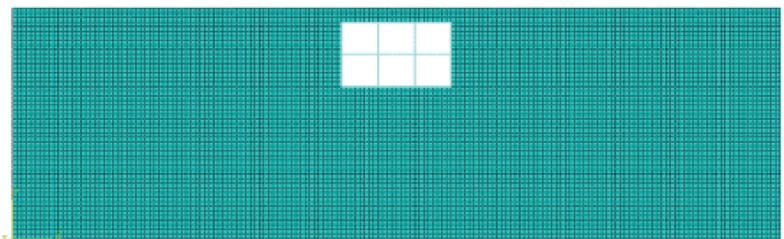

(b)

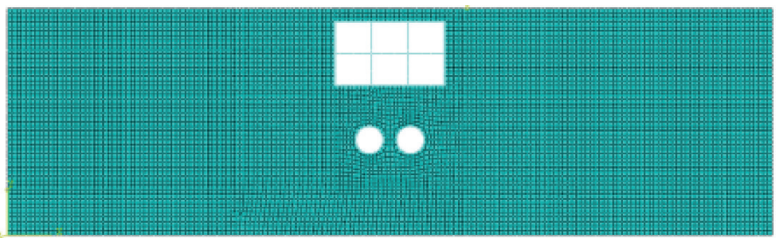

(d)

Figure 2: Finite element model. (a) Free-field model. (b) Soil-station model. (c) Soil-tunnel model. (d) Soil-tunnel-station model.

The size requirement of the grid unit is $L \leq \lambda / 10=v / 10 f$, where $\lambda$ is the shortest wavelength, $v$ is the equivalent shear wave velocity of the soil, and $f$ is the maximum frequency within the range of the ground motion energy to be considered. According to the soil material parameters, the equivalent shear wave velocity of the soil is approximately $220 \mathrm{~m} / \mathrm{s}$, and the ground motion energy is mainly concentrated within $10 \mathrm{~Hz}$. Considering $f=10 \mathrm{~Hz}$, we obtain $L \leq 2.2 \mathrm{~m}$. Therefore, the size of the grid unit is $1 \mathrm{~m}$.

Because the modal analysis is performed first, the vibration characteristics of the system are determined, and then, the transient analysis is performed. The boundary conditions of the modal analysis are as follows: the bottom of the model is set as the fixed boundary, the side is set to the vertical displacement constraint (i.e., the lateral slip boundary), and the top is free. In the transient analysis, in order to input the horizontal transverse seismic wave at the bottom of the model, the horizontal constraint of the bottom of the model is removed; the other aspects of the analysis are the same as in the modal analysis.

2.2. Constitutive Model. In this paper, the equivalent linear model, called the Davidenkov model, is used to consider the nonlinear characteristics of soil. Chazelas et al. [19] realized the secondary development of this model based on ABAQUS. The Davidenkov model can be described as

$$
\begin{aligned}
& \frac{G_{\mathrm{d}}}{G_{\max }}=1-\left[\frac{\left(\gamma_{\mathrm{d}} / \gamma_{\mathrm{r}}\right)^{2 B}}{1+\left(\gamma_{\mathrm{d}} / \gamma_{\mathrm{r}}\right)^{2 B}}\right]^{A}, \\
& \frac{\lambda}{\lambda_{\max }}=\left[\frac{1-G_{\mathrm{d}}}{G_{\max }}\right],
\end{aligned}
$$

where $A$ and $B$ are fitting constants; $\gamma_{\mathrm{r}}$ is the reference shear strain; $\gamma_{\mathrm{d}}$ is the instantaneous dynamic shear strain; $G_{\mathrm{d}}$ and $\lambda$ are the instantaneous dynamic shear modulus and damping ratio; and $G_{\max }$ and $\lambda_{\max }$ are the maximum dynamic shear modulus and maximum damping ratio. When $A=1, B=0.5$, the Davidenkov model degenerates into the common Hardin-Drnevich model. Based on the existing dynamic test data of soil, different types of soils are selected with different $A$ and $B$ values, and the initial damping ratio is 0.003 .

The soil body adopts the solid element, and the unit type is CPE4R [20]. Because the equivalent nonlinear Davidenkov model is employed, the damping characteristics are considered in the model. The tunnel structure and station structure adopt the beam unit of unit type B21 [20], and the tunnel and the station adopt the elastic model. The calculation parameters of each material are shown in Table 1. The soil and station and the soil and tunnel are in tie contact, that is, the relative displacement of the contact interface is not considered. 
TABLe 1: Calculation parameters of each material.

\begin{tabular}{lccc}
\hline Material & Density $\left(\mathrm{kg} / \mathrm{m}^{3}\right)$ & Elastic modulus $(\mathrm{MPa})$ & Poisson's ratio \\
\hline Soft soil $(0-40 \mathrm{~m})$ & 1800 & 208 & 0.45 \\
Hard soil $(40-50 \mathrm{~m})$ & 2000 & 917 & 0.3 \\
Concrete (station and tunnel) & 2500 & $3.5 \times 10^{4}$ & 0.2 \\
\hline
\end{tabular}

2.3. Input Seismic Wave. The famous El-Centro wave is selected firstly in the paper, and the amplitude of the input seismic wave was adjusted to $0.1 \mathrm{~g}$ ( $\mathrm{g}$ is the gravitational acceleration) according to Chinese Code. Then, in order to compare the seismic response of the tunnel-soil-station system under different seismic excitations, Kobe wave is selected for comparison, whose time history and spectrum curves are shown in Figure 3.

The calculation uses the display algorithm; the step time of the calculation is taken as $0.002 \mathrm{~s}$, and the calculation time is taken uniformly as $30 \mathrm{~s}$.

\section{Calculation Conditions}

3.1. Test Conditions. El-Centro wave (near-field wave) ground motion is selected in the seismic response analysis. The acceleration time-history curve of the seismic wave and its Fourier spectrum curve are shown in Figure 3. The seismic response law of the structural system under the action of seismic waves is analyzed. The specific working conditions are shown in Table 2. There are 18 working conditions. In Tables $2, S$ represents the net spacing between the two tunnels, and $H$ represents the net distance between the top of the tunnel and the bottom of the station.

3.2. Test Points Program of Models. To monitor the seismic response of the soil and structure, the measuring points are arranged at equal intervals on the surface and in the depth direction of the soil, and the acceleration, velocity, and displacement response of the soil and structure are mainly monitored. The specific arrangement of the test points is shown in Figure 4. Due to the symmetrical structure, the surface test points are only on the semistructure and are arranged as one point every $4 \mathrm{~m}$; the arrangement in the depth direction is one point every $2 \mathrm{~m}$. The station measurement point is on the middle column, and the tunnel measurement points are at the top and bottom.

\section{Verification of Numerical Analysis}

In order to ensure the accuracy of the numerical simulation, this section verifies the tunnel shaking table test in reference [15].

4.1. Verification of Modal Analysis. In order to verify the calculation model thoroughly, two models are both used in the paper. According to the actual size of the model box in reference [15], a $1 \mathrm{~m} \times 1.6 \mathrm{~m}$ model is established (Figure $5(\mathrm{a})$ ), and a prototype with a size of $160 \mathrm{~m} \times 32 \mathrm{~m}$ is established according to the similarity relationship (Figure 5(b)). The calculation model is established as discussed in Section 2, and the soil parameters are obtained according to the values in the reference. The first-order frequencies of the model and the prototype are $36.948 \mathrm{~Hz}$ and $2.748 \mathrm{~Hz}$, respectively. This shows a good agreement with the theoretical calculations of $37 \mathrm{~Hz}$ and $2.74 \mathrm{~Hz}$; the relative errors are $0.14 \%$ and $0.29 \%$, respectively, indicating the correctness of the modal analysis process.

4.2. Verification of Dynamic Analysis. Because the input seismic excitation selected in the shaking table test in the literature cannot be obtained, the classical El-Centro wave is used to verify the relationship diagram shown in Figure 21 (Figure 6(a) in this paper) in reference [15]. A free-field model (FF model) and a model containing an underground tunnel (SF model) are established, and the amplification factor at $V_{S}=100 \mathrm{~m} / \mathrm{s}$ is obtained, as shown in Figure 6(b).

It can be seen from Figure 6 that the simulation results in this paper are similar to those in reference [15]. When the dimensionless distance $X / a=0$, the amplification factor is the smallest; when $X / a=3$ (or 2), the amplification factor is the largest; and when $X / a>6$, the amplification factor tends to 1 . Despite the influence of different factors such as input seismic waves, the calculation results in this paper and the experimental data in [15] show only a slight difference in amplitude. They maintain a good agreement on the regular trend, and the differences are within the acceptable error range. Therefore, the dynamic analysis model and the method followed in this paper can be considered reasonable and feasible and can be used for subsequent parameter analysis.

\section{Analysis of Calculation Results}

5.1. Modal Analysis. The modal analysis of the established model is carried out to determine the vibration frequency characteristics of each working condition. The first 3 frequencies of the free field, soil-station model, soil-shallow buried tunnel model, and the corresponding soil-stationshallow buried tunnel model are shown in Table 3 .

It can be seen from the Table 3 that (1) $f=1.1 \mathrm{~Hz}$ is calculated based on the theoretical formula $f=V / 4 H$ for the self-vibration characteristics of the free-field soil. It is closer to the frequency of the model in the table, indicating the correctness of the model. (2) The fundamental frequencies of the working conditions are similar, and the underground structure has no significant influence on the dynamic characteristics of the system. Its influence is considered negligible from the engineering point of view. 


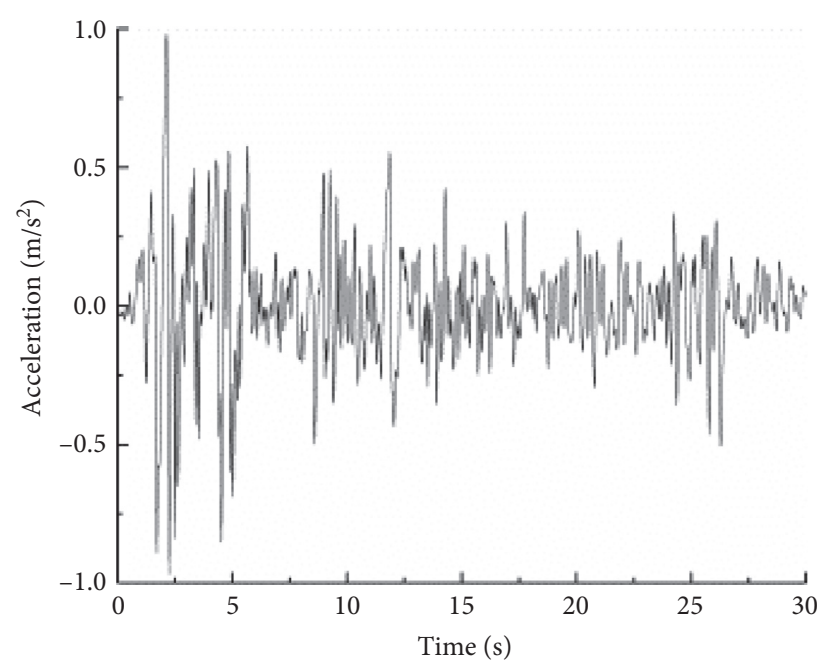

(a)

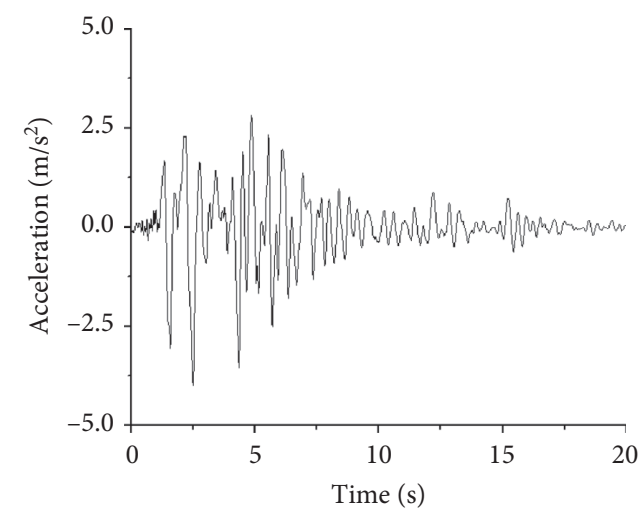

(c)

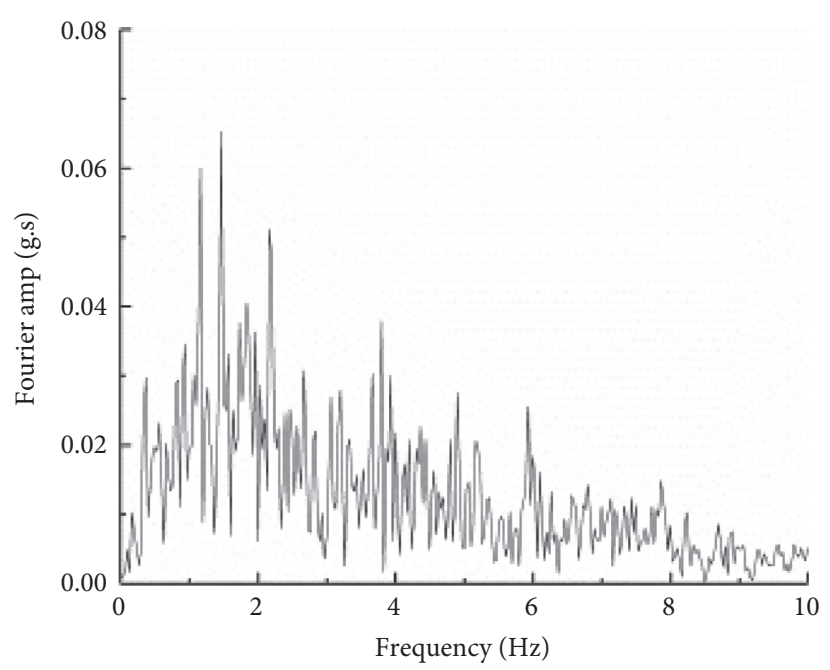

(b)

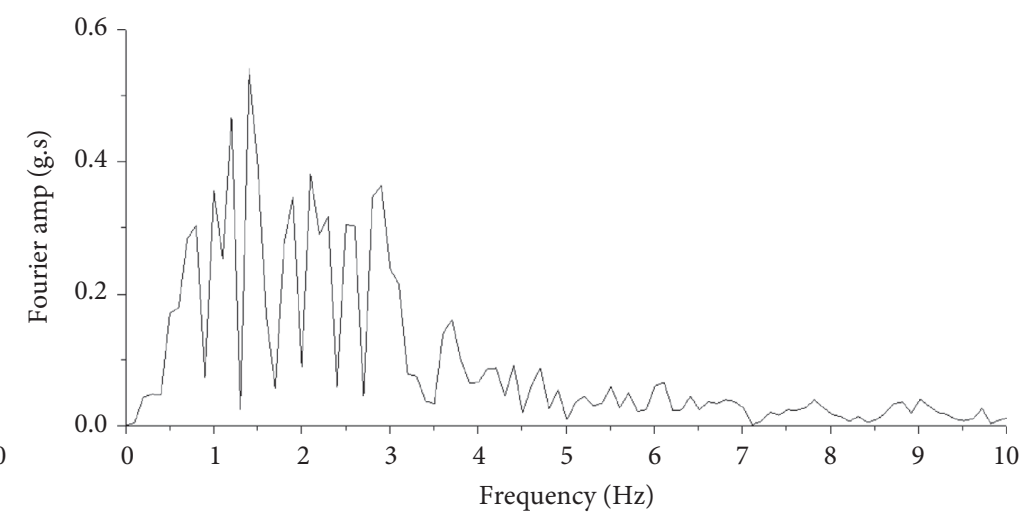

(d)

Figure 3: Time history and spectrum curves of El-Centro wave and Kobe wave. (a) Time history curve of El-Centro wave. (b) Frequency curve of El-Centro wave. (c) Time history curve of Kobe wave. (d) Frequency curve of Kobe wave.

TABle 2: Calculation conditions.

\begin{tabular}{|c|c|c|c|c|}
\hline Set & Model type & Parameters (m) & & Input motion \\
\hline SS1 & Soil-station & Buried depth is 3 & & \multirow{16}{*}{ El-Centro wave and its amplitude are adjusted to $0.1 \mathrm{~g}$. } \\
\hline ST2 & & & $S=3$ & \\
\hline ST3 & & & $S=6$ & \\
\hline ST4 & & Buried depth is 17.5 & $S=12$ & \\
\hline ST5 & & & $S=18$ & \\
\hline ST6 & Soil-tunnel & & $S=3$ & \\
\hline ST7 & & & $S=6$ & \\
\hline ST8 & & Buried depth is 26 & $S=12$ & \\
\hline ST9 & & & $S=18$ & \\
\hline STS10 STS11 & \multirow{4}{*}{ Soil-tunnel-station } & $S=3$ & $\begin{array}{c}H=0.5 \\
H=9\end{array}$ & \\
\hline STS12 STS13 & & $S=6$ & $\begin{array}{c}H=0.5 \\
H=9\end{array}$ & \\
\hline STS14 STS15 & & $S=12$ & $\begin{array}{c}H=0.5 \\
H=9\end{array}$ & \\
\hline STS16 STS17 & & $S=18$ & $\begin{array}{c}H=0.5 \\
H=9\end{array}$ & \\
\hline FF18 & Free-field & & & \\
\hline FF19 & Free-field & & & \\
\hline SS20 & Soil-station & Buried depth is 3 & & \\
\hline
\end{tabular}




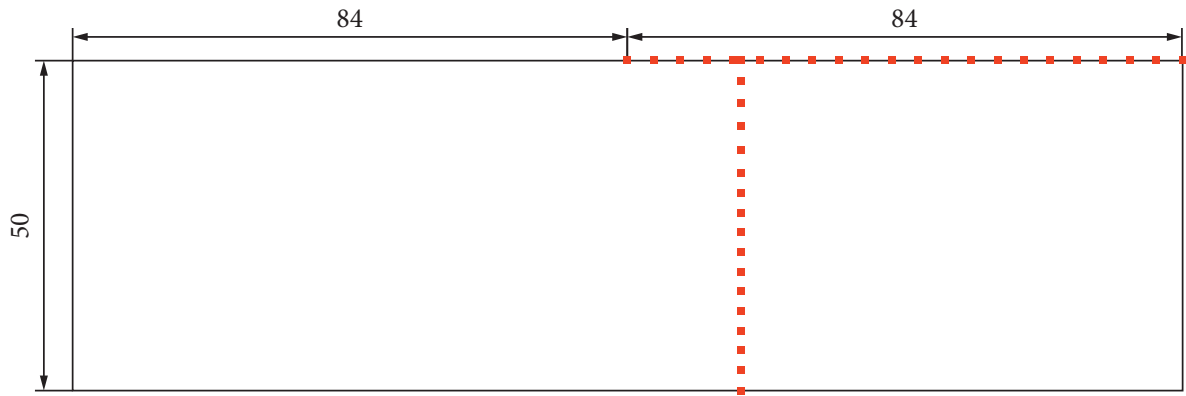

(a)

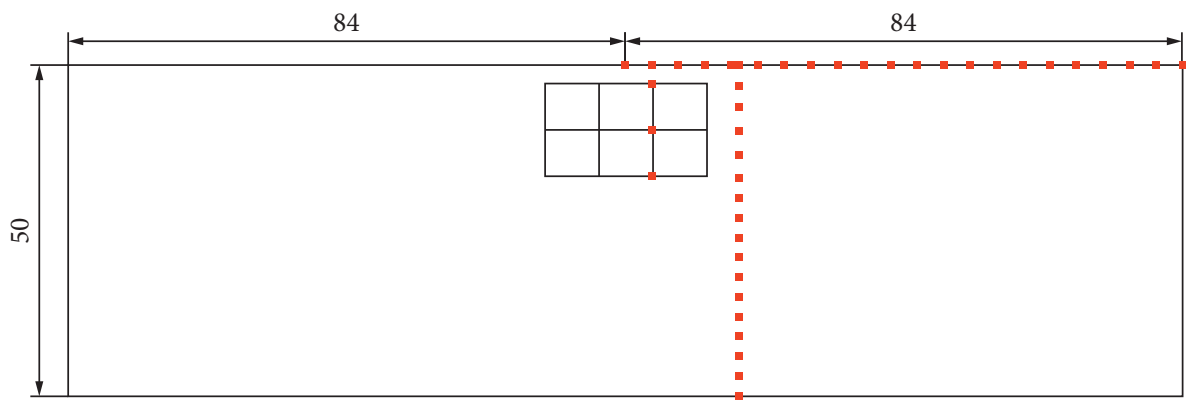

(b)

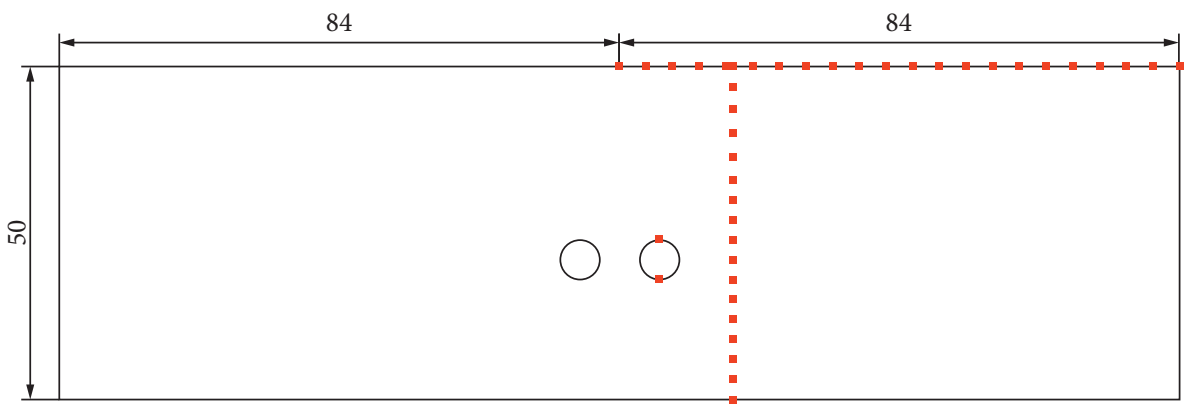

(c)

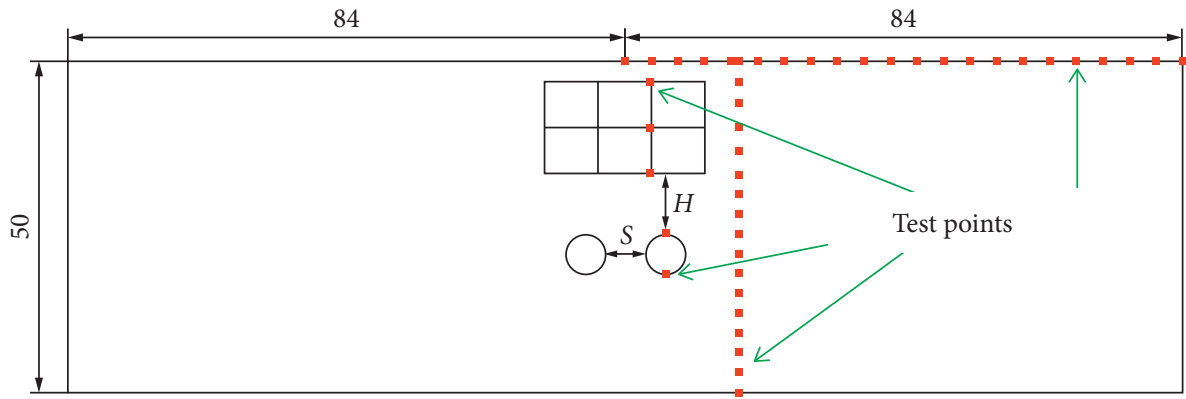

(d)

Figure 4: Arrangement of test points (unit: m). (a) Free-field model. (b) Soil-station model. (c) Soil-tunnel model. (d) Soil-tunnel-station model.

\subsection{Soil Response Analysis}

5.2.1. Acceleration Analysis of the Midpoint of the Surface. Figure 7 shows the acceleration-time history diagram of the midpoint of the surface of the free field under the action of $0.1 \mathrm{~g}$ El-Centro wave. The magnitudes of the acceleration at the midpoint of the ground are listed in Table 4 and compared with those of the free field. To facilitate quantitative analysis, the influence coefficient of the underground structure on soil is defined as

$$
R_{1}=\frac{\left(A_{\mathrm{CS}}-A_{0}\right)}{A_{0}},
$$

where $A_{0}$ represents the positive acceleration amplitude of the center of the free-field table, and $A_{\mathrm{CS}}$ represents the 


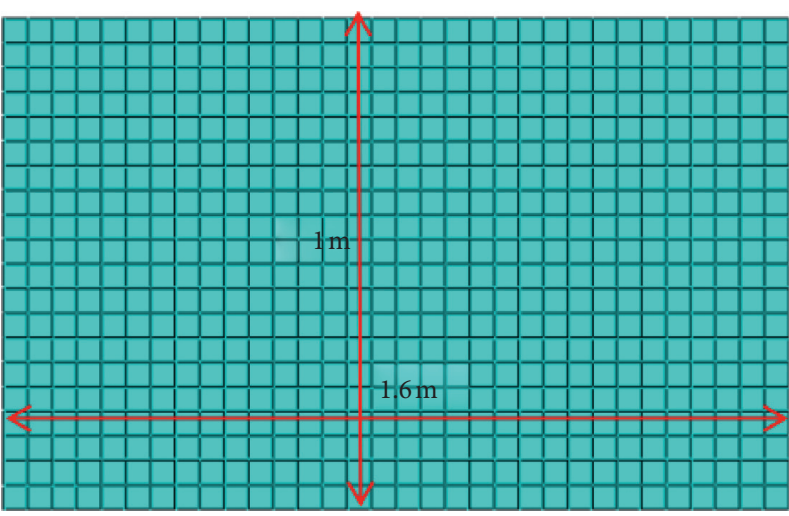

$f_{1}=36.948 \mathrm{~Hz}$

(a)

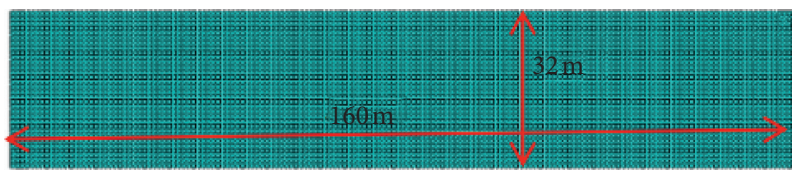

$f_{1}=2.748 \mathrm{~Hz}$

Figure 5: Numerical model and frequency. (a) Model. (b) Prototype.

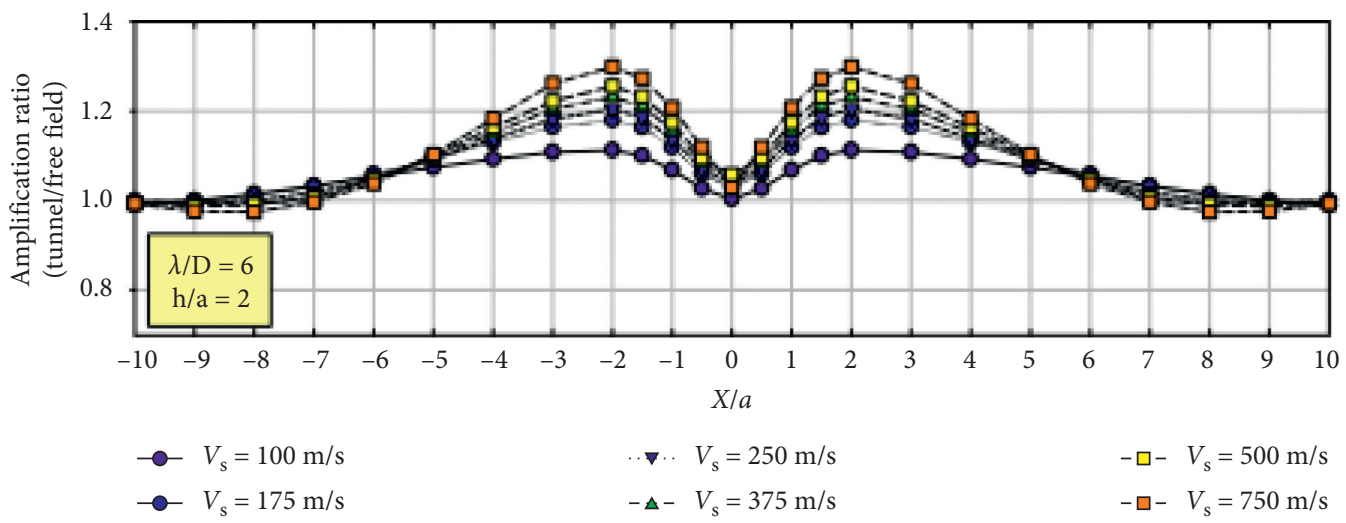

(a)

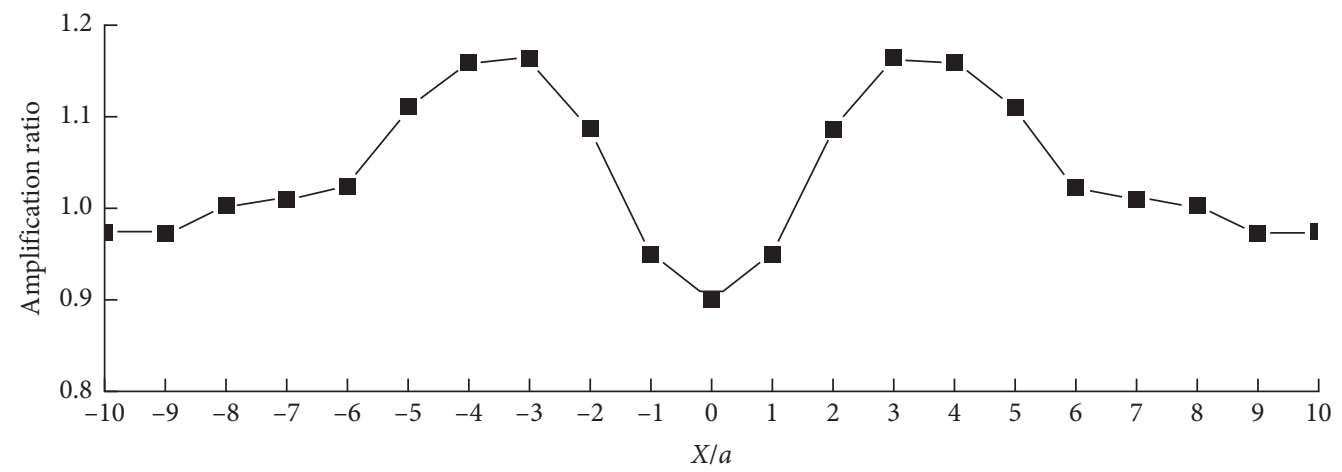

(b)

Figure 6: Comparison of simulation results. (a) Results in Reference [15]. (b) Simulation results of this paper.

TABle 3: First three orders of natural frequency under different conditions (unit: $\mathrm{Hz}$ ).

\begin{tabular}{lccc}
\hline Set & First order & Second order & Third order \\
SS1 & 1.203 & 1.723 & 2.256 \\
ST2 & 1.184 & 1.618 & 2.216 \\
STS10 & 1.204 & 1.723 & 2.266 \\
FF18 & 1.187 & 1.566 & 2.148 \\
\hline
\end{tabular}




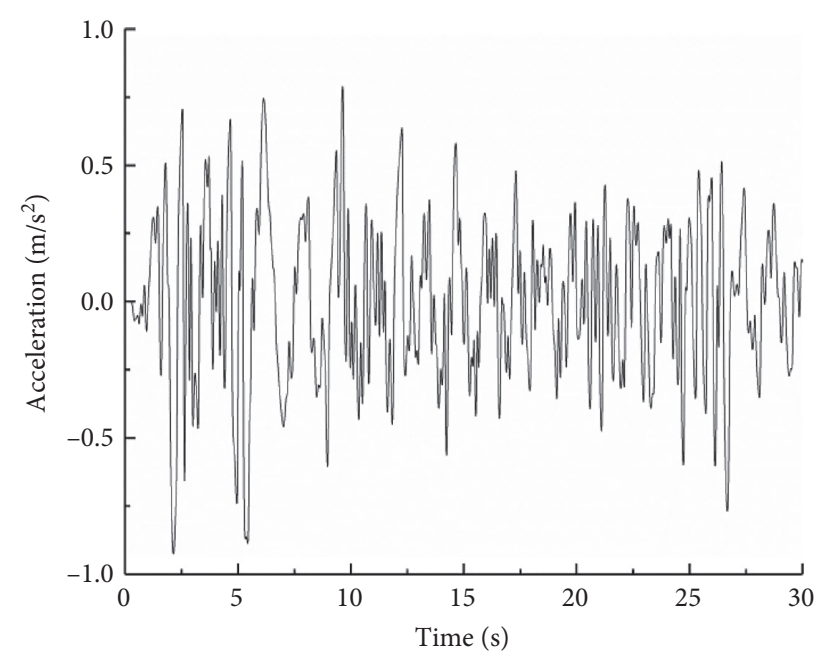

Figure 7: Comparison of simulation results.

TABLE 4: Surface midpoint acceleration under different conditions.

\begin{tabular}{lccc}
\hline Set & $S(\mathrm{~m})$ & Acceleration amplitude $\left(\mathrm{m} / \mathrm{s}^{2}\right)$ & $R_{1}(\%)$ \\
\hline FF18 & & 0.925 & 1.174 \\
SS1 & 3 & 0.925 & 0 \\
ST2 & 6 & 0.933 & 0.864 \\
ST3 & 12 & 0.913 & -1.29 \\
ST4 & 18 & 0.929 & 0.432 \\
ST5 & 3 & 0.927 & 0.216 \\
\hline ST6 & 6 & 0.926 & 0.108 \\
ST7 & 12 & 0.924 & -0.108 \\
ST8 & 18 & 0.924 & -0.108 \\
ST9 & 3 & 1.170 & 26.486 \\
STS10 & 6 & 1.167 & 26.162 \\
STS12 & 12 & 1.163 & 25.729 \\
STS14 & 18 & 1.157 & 25.081 \\
STS16 & 3 & 1.157 & 25.081 \\
STS11 & 6 & 1.158 & 25.189 \\
STS13 & 12 & 1.162 & 25.622 \\
STS15 & 18 & 1.160 & 25.405 \\
STS17 & & & \\
\hline
\end{tabular}

positive acceleration amplitude of the center of the surface when the underground structure exists.

It can be seen from the Table 4 that the station structure has small buried depth and large cross-sectional size, which have a great influence on the surface acceleration. The station structure significantly increases the acceleration of the surface center, and the impact amplitude is approximately $25 \%$. However, owing to the large depth and small size of the tunnel, the impact on the surface acceleration is small, which can be neglected.

5.2.2. Influence of Underground Structure on Soil Response. Taking the deep buried tunnel as an example, the effects of the underground structure on the surface acceleration response and soil displacement along the depth of the soil are explored. The surface acceleration amplitude curves of the four systems (Figure 8) and the soil displacement map in the depth direction (Figure 9) are presented.
It can be seen from the figure that the degree of influence of the station on the ground surface acceleration is greater than that of the tunnel; the influence of the station on the surface acceleration is approximately five times the station width $(60 \mathrm{~m}$ on both sides of the center of the earth's surface). In this range, the surface acceleration is obviously larger than the free field, and the surface acceleration outside this range is different much to free field. Based on the displacement of the soil in the depth direction, the existence of the underground structure is beneficial in reducing the lateral displacement of the soil, and the influence of the station structure is greater than the influence of the tunnel structure. The influence of the station structure plays a major role when the station and the tunnel exist simultaneously.

5.2.3. Influence of the Seismic Wave Type. The soil and structural responses may be different for different types of seismic waves. The soil response is taken as an example to 


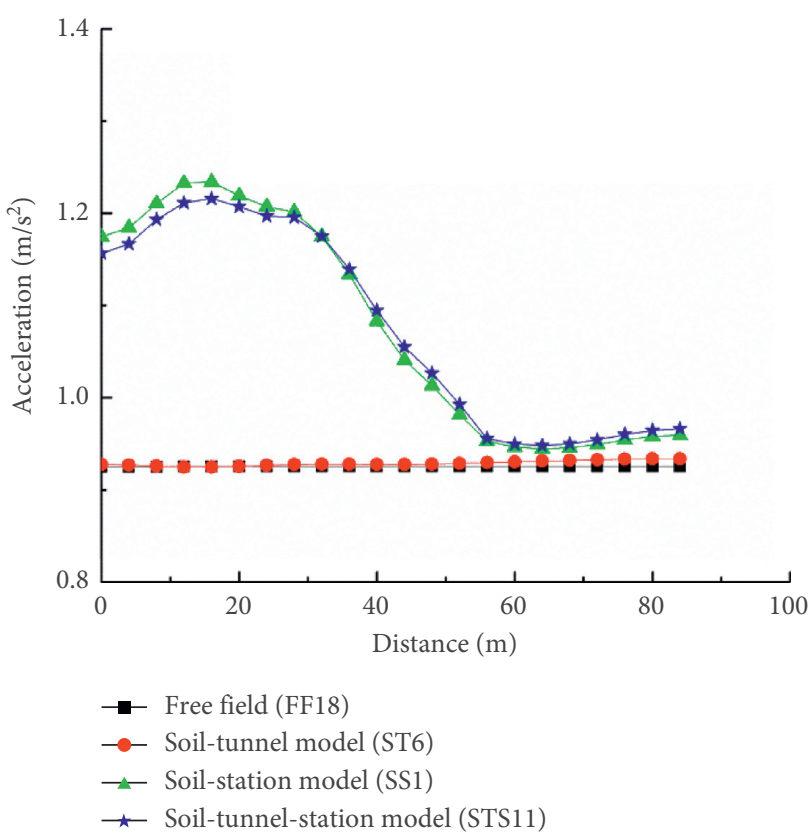

FIGURE 8: Surface acceleration amplitude under El-Centro wave.

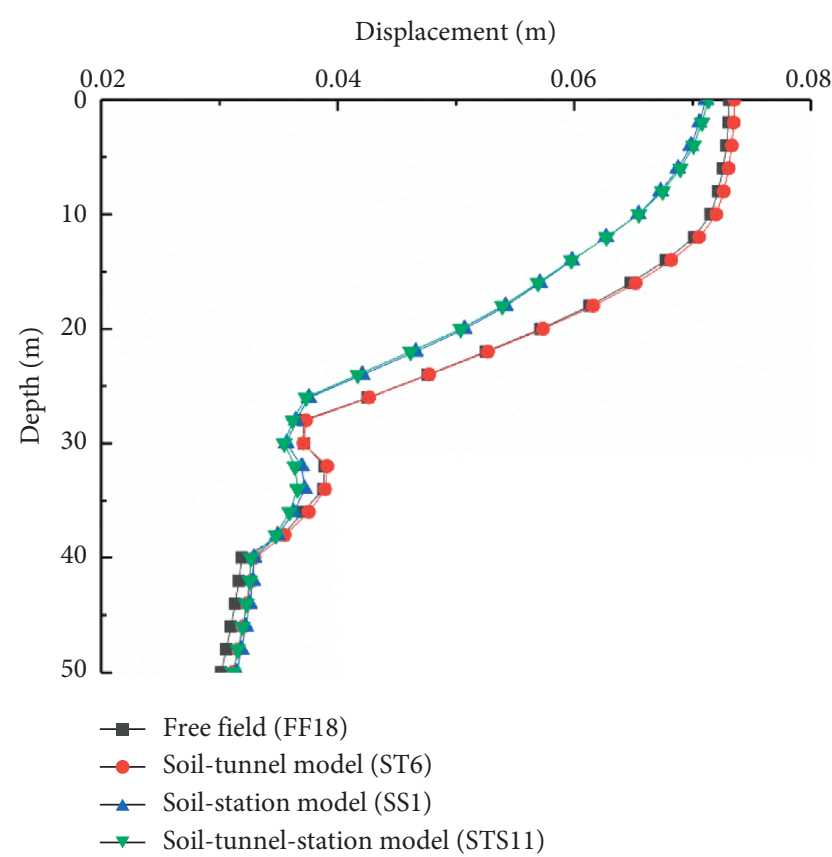

Figure 9: Soil displacement in the depth direction under El-Centro wave.

analyze the effects of different types of seismic waves and the surface acceleration of the free field, and the soil-station model (Figure 10) and soil displacement map are obtained in the depth direction (Figure 11) under different seismic waves.

It can be seen from the figure that the influence law and degree of influence of different seismic waves on the soil response are different. Based on the surface acceleration response and soil displacement response, the influence of the El-Centro wave is larger than that of the Kobe wave.

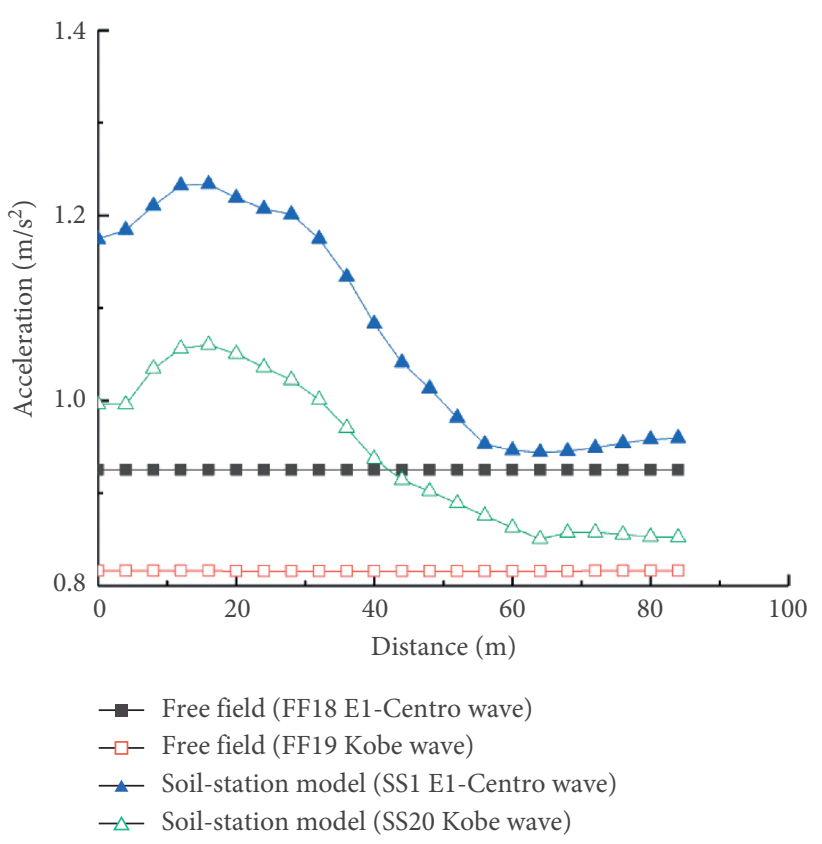

Figure 10: Surface acceleration under different seismic waves.

5.3. Analysis of the Influence of Tunnel on Station Response. This section compares the different aspects of the seismic response of the station with and without tunnels. To facilitate the analysis of the problem, the influence coefficient of the tunnel on the station is defined as

$$
R_{2}=\frac{C_{\mathrm{CS}}-C_{\mathrm{C}}}{C_{\mathrm{C}}}
$$

where $C_{\mathrm{C}}$ represents the response of the station in the earthstation system, and $C_{\mathrm{CS}}$ represents the response of the station in the earth-tunnel-station system.

\subsubsection{Acceleration Analysis of the Top of the Middle Column} of the Station. In order to explore the influence of the acceleration response at the top of the column in the station with the tunnel passing underneath, the acceleration response of the station center column is given for the case when only the station structure is present (Figure 12). Table 5 lists the acceleration amplitudes for the station structures with and without the tunnel.

It can be seen from the Table 5 that the existence of the tunnel can reduce the acceleration of the column in the station by approximately $10 \%$. Generally, the influence of the net spacing between the tunnels is not obvious. The greater the distance between the tunnel and the station, the smaller the acceleration of the column in the station.

5.3.2. Analysis of the Displacement Angle between Floors of the Station. There are three measuring points on the column in the station, which are located at the top, middle, and bottom of the column. The displacement response of these points can provide the difference in the interlayer displacement between the upper and lower layers and the 


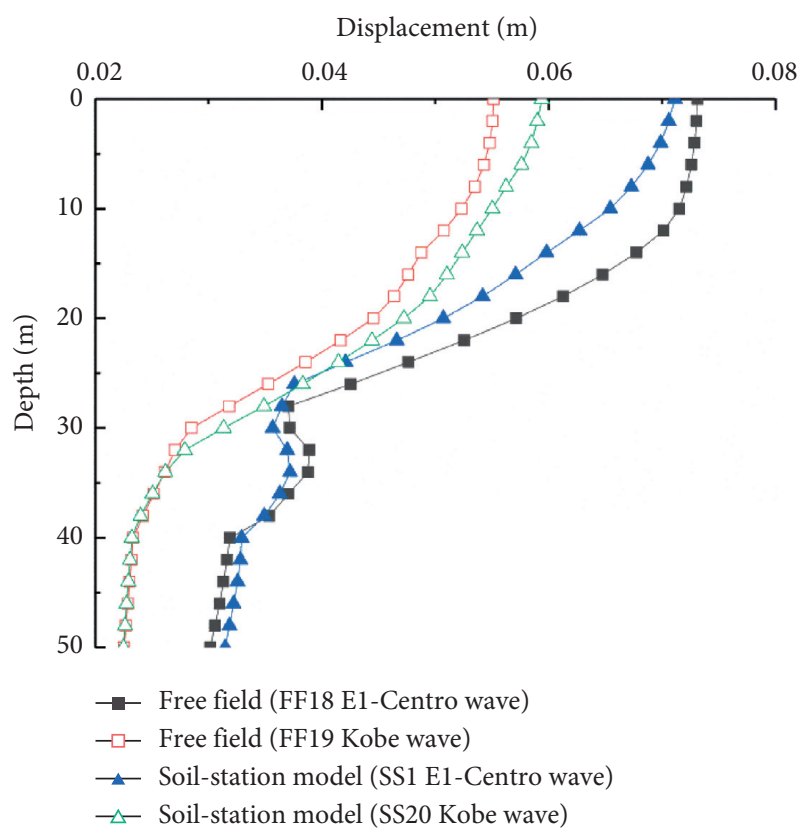

FIGURE 11: Displacement of soil in depth direction under different seismic waves.

displacement angle between the layers. The time-history map of the displacement angle between the stations is shown in Figure 13 when only the station structure is present. The maximum displacement angle between the stations in other systems is given in Table 6 .

It can be seen from the graph that the interlayer displacement angle of the lower layer of the station structure is large; the existence of the tunnel structure increases the interlayer displacement angle of the station structure. The smaller the spacing between the tunnel and the station and the smaller the spacing between the tunnels, the greater the increase in the displacement angle between the stations. When the distance between the tunnel and the station is large, the change in the net spacing between the tunnels will not cause a large change in the displacement angle between the stations.

5.3.3. Internal Force Analysis of the Station. By observing the bending moment cloud diagram of the station structure, it is found that the maximum bending moment always appears at the corner of the station at $2.180 \mathrm{~s}$. The bending moment cloud at $2.18 \mathrm{~s}$ is shown in Figure 14. The maximum values (absolute value) of the bending moment of the left corner of the station for other conditions are listed in Table 7.

It can be seen from the graph that the bending moment at the corner of the station structure is large and stress concentration can easily occur. When the distance between the tunnel and the station is small, the existence of the tunnel increases the bending moment of the station, but the overall impact is not significant.

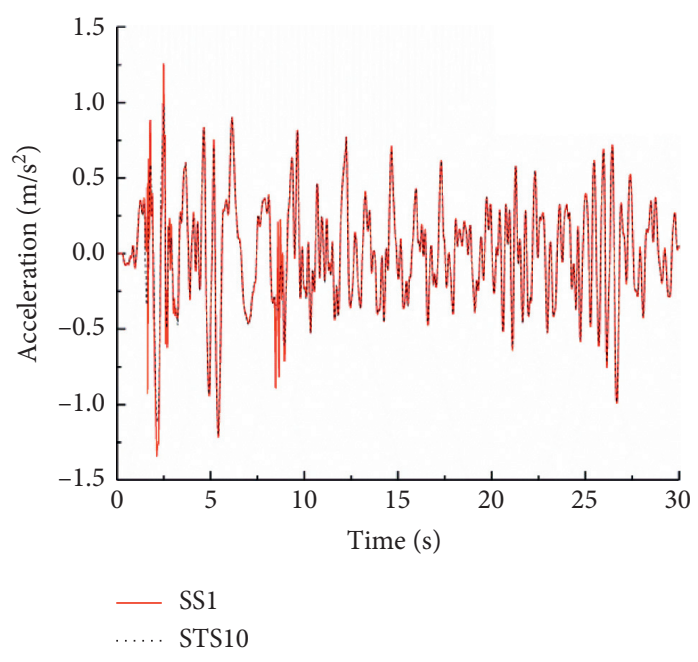

Figure 12: Acceleration at the top of the station.

TABle 5: Acceleration at the top of the interior column.

\begin{tabular}{lccc}
\hline Set & $S(\mathrm{~m})$ & Acceleration amplitude $\left(\mathrm{m} / \mathrm{s}^{2}\right)$ & $R_{2}(\%)$ \\
\hline SS1 & & 1.345 & \\
STS10 & 3 & 1.207 & -10.260 \\
STS12 & 6 & 1.204 & -10.483 \\
STS14 & 12 & 1.201 & -10.706 \\
STS16 & 18 & 1.201 & -10.706 \\
STS11 & 3 & 1.198 & -10.929 \\
STS13 & 6 & 1.199 & -10.855 \\
STS15 & 12 & 1.200 & -10.781 \\
\hline
\end{tabular}

5.4. Analysis of the Influence of the Station on Tunnel Response. This section analyzes the response of the tunnel and discusses the impact of the station on the dynamic response of the tunnel. To facilitate the analysis of the problem, the influence coefficient of the station on the tunnel is defined as

$$
R_{3}=\frac{S_{\mathrm{CS}}-S_{\mathrm{S}}}{S_{\mathrm{S}}},
$$

where $S_{S}$ represents the response of the tunnel in the soiltunnel system and $S_{\mathrm{CS}}$ represents the response of the tunnel in the corresponding soil-tunnel-station system.

5.4.1. Analysis of Acceleration at the Top of the Tunnel. Taking the soil-shallow buried tunnel with a tunnel spacing of $3 \mathrm{~m}$ as an example, the acceleration diagram of the top of the tunnel is shown in Figure 15. The maximum accelerations of the top of the tunnel under other conditions are shown in Table 8.

It can be seen from the chart that stations influence shallow buried tunnels and deep buried tunnels differently. In the case of a shallow buried tunnel (distance between the shallow buried tunnel and station is $0.5 \mathrm{~m}$ ), the presence of a station slightly enlarges the acceleration of the tunnel top. The amplification is between $2 \%$ and $4 \%$; 


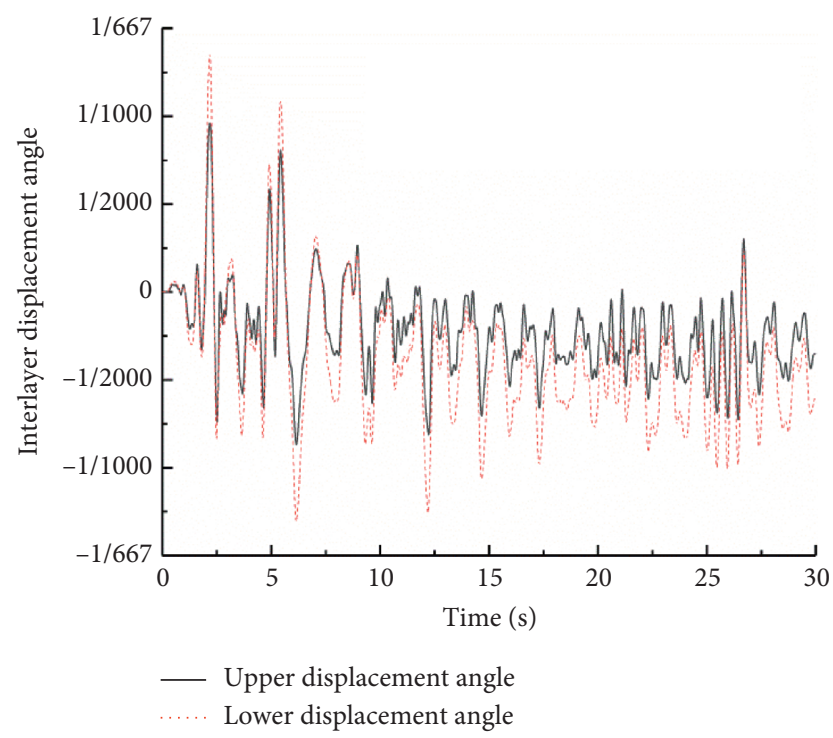

Figure 13: Interlayer displacement angle of the station structure.

TABLE 6: Interlayer displacement angle of station structure for various conditions.

\begin{tabular}{|c|c|c|c|c|c|}
\hline \multirow{2}{*}{ Set } & \multirow{2}{*}{$S(\mathrm{~m})$} & \multicolumn{2}{|c|}{ Maximum displacement angle } & \multicolumn{2}{|c|}{$R_{2}(\%)$} \\
\hline & & Upper layer & Lower layer & Upper layer & Lower layer \\
\hline SS1 & & $1 / 1041$ & $1 / 739$ & & \\
\hline STS10 & 3 & $1 / 1013$ & $1 / 712$ & 2.813 & 3.769 \\
\hline STS12 & 6 & $1 / 1013$ & $1 / 716$ & 2.813 & 3.178 \\
\hline STS14 & 12 & $1 / 1015$ & $1 / 714$ & 2.604 & 3.474 \\
\hline STS16 & 18 & $1 / 1016$ & $1 / 718$ & 2.500 & 2.882 \\
\hline STS11 & 3 & $1 / 1026$ & $1 / 733$ & 1.458 & 0.813 \\
\hline STS13 & 6 & $1 / 1026$ & $1 / 733$ & 1.458 & 0.813 \\
\hline STS15 & 12 & $1 / 1026$ & $1 / 731$ & 1.458 & 1.034 \\
\hline STS17 & 18 & $1 / 1026$ & $1 / 731$ & 1.458 & 1.034 \\
\hline
\end{tabular}

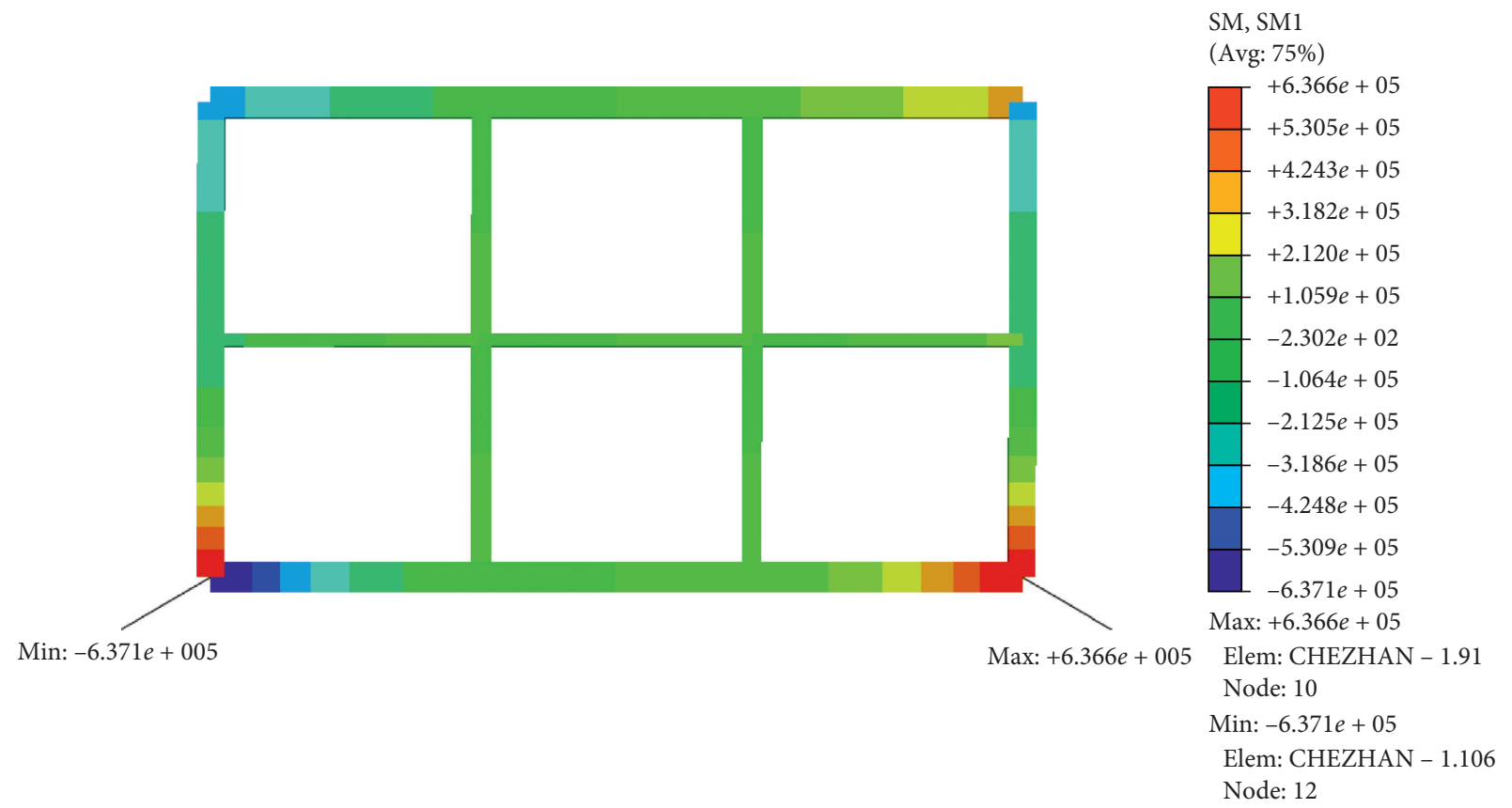

FIGURE 14: Bending moment cloud diagram of the station structure. 
TABLE 7: Maximum bending moment at the corner of the station.

\begin{tabular}{lccc}
\hline Set & $S(\mathrm{~m})$ & Maximum bending moment $(\mathrm{N} \cdot \mathrm{m})$ & $R_{2}(\%)$ \\
\hline SS1 & & 637063 & 2.942 \\
STS10 & 3 & 655808 & 1.726 \\
STS12 & 6 & 648061 & 1.575 \\
STS14 & 12 & 647094 & 0.642 \\
STS16 & 18 & 641156 & 0.296 \\
STS11 & 3 & 638948 & -0.113 \\
STS13 & 6 & 636342 & -0.455 \\
STS15 & 12 & 634166 & -0.356 \\
STS17 & 18 & 634791 & \\
\hline
\end{tabular}

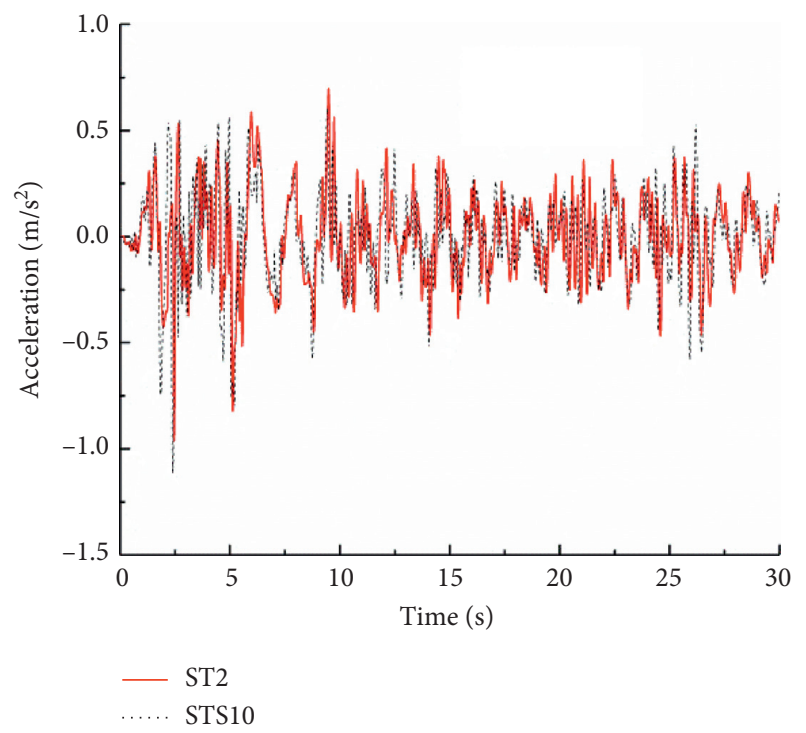

FIgURE 15: Acceleration at the top of the tunnel.

TABLE 8: Acceleration at the top of the tunnel under different conditions.

\begin{tabular}{|c|c|c|c|}
\hline Set & $S(\mathrm{~m})$ & Acceleration $\left(\mathrm{m} / \mathrm{s}^{2}\right)$ & $R_{3}(\%)$ \\
\hline $\begin{array}{l}\text { ST2 } \\
\text { STS10 }\end{array}$ & 3 & $\begin{array}{l}0.961 \\
0.979\end{array}$ & 1.873 \\
\hline $\begin{array}{l}\text { ST3 } \\
\text { STS12 }\end{array}$ & 6 & $\begin{array}{l}0.984 \\
1.004 \\
\end{array}$ & 2.033 \\
\hline $\begin{array}{l}\text { ST4 } \\
\text { STS14 } \\
\end{array}$ & 12 & $\begin{array}{l}1.002 \\
1.026 \\
\end{array}$ & 2.395 \\
\hline $\begin{array}{l}\text { ST5 } \\
\text { STS16 }\end{array}$ & 18 & $\begin{array}{l}0.998 \\
1.037\end{array}$ & 3.908 \\
\hline $\begin{array}{l}\text { ST6 } \\
\text { STS11 } \\
\end{array}$ & 3 & $\begin{array}{l}1.217 \\
1.115\end{array}$ & -8.381 \\
\hline $\begin{array}{l}\text { ST7 } \\
\text { STS13 }\end{array}$ & 6 & $\begin{array}{l}1.232 \\
1.144 \\
\end{array}$ & -8.81 \\
\hline $\begin{array}{l}\text { ST8 } \\
\text { STS15 }\end{array}$ & 12 & $\begin{array}{l}1.257 \\
1.182 \\
\end{array}$ & -7.143 \\
\hline $\begin{array}{l}\text { ST9 } \\
\text { STS17 }\end{array}$ & 18 & $\begin{array}{l}1.264 \\
1.189 \\
\end{array}$ & -5.934 \\
\hline
\end{tabular}

the larger the net spacing between the tunnels, the more obvious the amplification effect. In the case of a deep buried tunnel, the presence of the station weakens the acceleration response at the top of the tunnel by $5 \%-9 \%$; the degree of attenuation decreases as the spacing between the tunnels increases. 


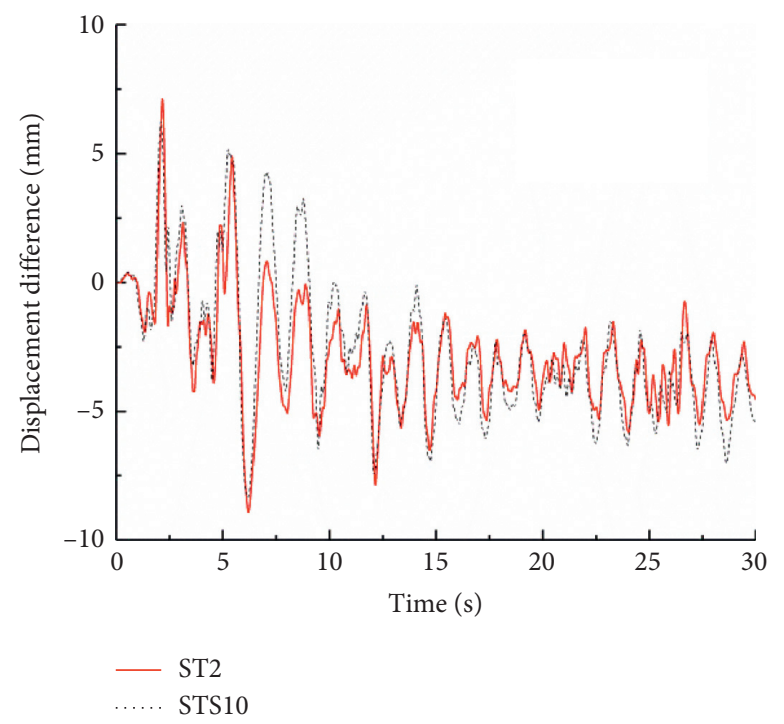

Figure 16: Relative displacement between the top and bottom of the tunnel.

TABLE 9: Displacement difference between the top and bottom of the tunnel under various conditions.

\begin{tabular}{|c|c|c|c|}
\hline Set & $S(\mathrm{~m})$ & Relative displacement $(\mathrm{mm})$ & $R_{3}(\%)$ \\
\hline $\begin{array}{l}\text { ST2 } \\
\text { STS10 } \\
\end{array}$ & 3 & $\begin{array}{l}8.925 \\
7.608 \\
\end{array}$ & -14.756 \\
\hline $\begin{array}{l}\text { ST3 } \\
\text { STS12 } \\
\end{array}$ & 6 & $\begin{array}{l}9.135 \\
8.161 \\
\end{array}$ & -10.662 \\
\hline $\begin{array}{l}\text { ST4 } \\
\text { STS14 } \\
\end{array}$ & 12 & $\begin{array}{l}9.271 \\
8.463 \\
\end{array}$ & -8.715 \\
\hline $\begin{array}{l}\text { ST5 } \\
\text { STS16 } \\
\end{array}$ & 18 & $\begin{array}{l}9.347 \\
8.962 \\
\end{array}$ & -4.119 \\
\hline $\begin{array}{l}\text { ST6 } \\
\text { STS11 } \\
\end{array}$ & 3 & $\begin{array}{c}11.367 \\
8.353 \\
\end{array}$ & -26.515 \\
\hline $\begin{array}{l}\text { ST7 } \\
\text { STS13 } \\
\end{array}$ & 6 & $\begin{array}{c}11.532 \\
8.654 \\
\end{array}$ & -24.957 \\
\hline $\begin{array}{l}\text { ST8 } \\
\text { STS15 } \\
\end{array}$ & 12 & $\begin{array}{c}11.602 \\
9.277 \\
\end{array}$ & -20.067 \\
\hline $\begin{array}{l}\text { ST9 } \\
\text { STS17 }\end{array}$ & 18 & $\begin{array}{c}11.753 \\
9.796\end{array}$ & -16.651 \\
\hline
\end{tabular}

SM, SM1

(Avg: 100\%)

$+1.118 e+05$
+
$+9.327 e+04$
$+7.471 e+04$
$+5.615 e+04$
+
$+3.759 e+04$
$+1.903 e+04$
$+4.696 e+02$
$-1.809 e+04$
$-3.665 e+04$
$-5.521 e+04$
$-7.377 e+04$
$-9.233 e+04$
$-1.109 e+05$

Max: $+1.118 e+05$

Node: SUIDAO -1.11

Min: $-1.109 e+05$

Node: SUIDAO - 1.17
Max: $+1.118 e+005$
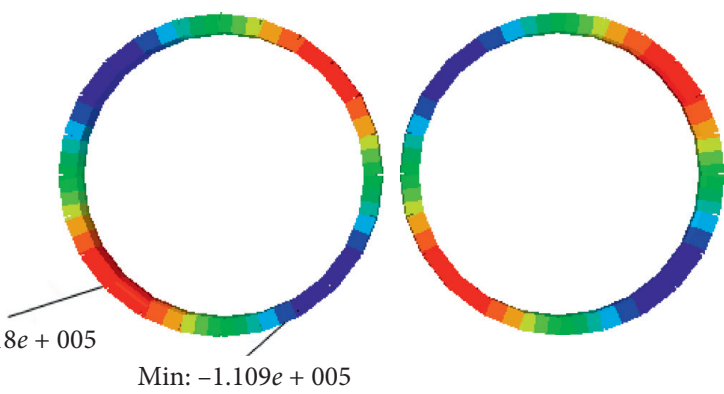

Min: $-1.109 e+005$

FIGURE 17: Bending moment cloud diagram of the tunnel structure. 
TABle 10: Maximum bending moment of the tunnel structure under various conditions.

\begin{tabular}{lccc}
\hline Set & $S(\mathrm{~m})$ & Maximum bending moment $(\mathrm{N} \cdot \mathrm{m})$ & $R_{3}(\%)$ \\
\hline ST2 & \multirow{2}{*}{3} & 111846 & 8.289 \\
STS10 & & 121117 & 1.835 \\
\hline ST3 & \multirow{2}{*}{6} & 113982 & -11.753 \\
STS12 & & 116074 & -9.873 \\
\hline ST4 & \multirow{2}{*}{12} & 114694 & -15.88 \\
STS14 & & 101214 & -13.706 \\
\hline ST5 & \multirow{2}{*}{18} & 117130 & -10.364 \\
STS16 & & 105566 & -11.681 \\
\hline ST6 & \multirow{2}{*}{3} & 135637 & \\
STS11 & & 117046 & \\
\hline ST7 & \multirow{2}{*}{6} & 139212 & \\
STS13 & & 123486 & \\
\hline ST8 & \multirow{2}{*}{12} & 140029 & \\
STS15 & & 141635 & \\
\hline ST9 & \multirow{2}{*}{18} & 125090 & \\
STS17 & & &
\end{tabular}

5.4.2. Analysis of the Displacement Difference between the Top and Bottom of the Tunnel. Taking the soil-shallow buried tunnel with a tunnel spacing of $3 \mathrm{~m}$ as an example, the displacement difference between the top and bottom of the tunnel is shown in Figure 16. The maximum displacement differences between the top and bottom of the tunnel for various conditions are shown in Table 9.

It can be seen from the chart that the station reduces the difference in the horizontal displacement between the top and bottom of the tunnel, and the degree of attenuation decreases with an increase in the spacing between the tunnels. However, the impact amplitudes of the shallow tunnel and deep tunnel are different. The attenuation for the shallow tunnel is $4 \%-15 \%$, whereas that for the deep tunnel is $16 \%-27 \%$.

5.4.3. Internal Force Analysis of the Tunnel. By observing the bending moment cloud diagram of the tunnel structure, it is found that the maximum bending moment appears in the $45^{\circ}$ direction of the tunnel structure. The bending moment cloud diagram of the tunnel structure in the soil-shallow buried tunnel system (when the tunnel spacing is $3 \mathrm{~m}$ ) is shown in Figure 17. The maximum value of the bending moment of the working tunnel structure is shown in Table 10.

It can be seen from the graph that the maximum bending moment of the tunnel structure appears in the $45^{\circ}$ direction of the tunnel section. The larger the spacing between the tunnels, the larger the bending moment on the tunnel; the influence of the station structure on the tunnel bending moment is inconsistent. In general, the presence of a station can reduce the bending moment of the tunnel structure.

\section{Conclusions}

In this paper, a two-hole tunnel underpass station model was established. The ABAQUS finite element software was used to analyze the seismic response. The seismic response law of the cross-underground structure was discussed. The following rules were obtained from the calculation and analysis:

(1) Influence of the underground structure on the dynamic response of soil: the station structure has a great impact whereas the tunnel structure has less impact on the surface response. The range within which the station structure has a great impact on the surface response is five times the width of the station. Within this range, the surface acceleration response increases significantly, whereas the influence outside this range is small. The tunnel has a large buried depth, and its influence on the surface response is basically negligible. The station depth is small because of which it has a great influence on the surface response. When the station and the tunnel structure exist simultaneously, the influence of the station structure plays a major role. Overall, the presence of underground structures reduces the horizontal displacement of the soil.

(2) Impact of the tunnel on the dynamic response of the station: the existence of the tunnel can reduce the acceleration of the column in the station by approximately $10 \%$; the impact of the net spacing between the tunnels is not obvious. When the distance between the tunnel and the station is large, the acceleration of the column in the station is greatly weakened. The existence of the tunnel structure increases the interlayer displacement angle of the station structure; the smaller the distance between the tunnel and the station and the smaller the spacing between the tunnels, the greater the increase in the displacement between the stations. The impact of the tunnel on the internal force response of the station is not significant.

(3) Impact of the station on the dynamic response of the tunnel: the station influences the acceleration of the shallow buried tunnel and the deep buried tunnel differently. In the case of the shallow buried tunnel, the existence of the station slightly amplifies the acceleration response at the top of the tunnel. In the case of the deep buried tunnel, the presence of the station weakens the acceleration response at the top of the tunnel. As the spacing between the tunnels increases, the degree of attenuation decreases. The presence of the station reduces the difference in displacement between the top and bottom of the tunnel, and with an increase in the spacing between the tunnels, the degree of attenuation decreases. The presence of the station is conducive to reducing the internal force of the tunnel.

At present, the research on seismic resistance of complex underground structure is limited, and the related research still needs further improvement. Underground structures tend to be large in size and traverse different strata. Moreover, they do not exist independently and have a complex environment. Therefore, it is 
necessary to consider more influencing factors, such as structural characteristics, changes in soil parameters, seismic excitation characteristics, spatial effects of ground motion effects, and aboveground buildings.

\section{Data Availability}

No data were used to support the findings of the study.

\section{Conflicts of Interest}

The authors declare that they have no conflicts of interest.

\section{Authors' Contributions}

Fuxue Sun conducted investigation on existing research results extensively and deeply and supervised the development of research work. Wang Guo-bo conceptualized the actual project, determined the reasonable modeling method, and acquired funds to ensure the success of the research work. Xiang-jun Peng was responsible for modelling and simulating actual engineering problems through software and data analysis. Zhou-zhou Jin verified the correctness and reliability of the results and wrote the original draft. Xiaochun $\mathrm{Li}$ administrated the actual project and provided necessary resources for the research. Jie-lin Zhao was responsible for reviewing and editing the original draft to improve overall English language usage, readability, clarity, grammar, and spelling.

\section{Acknowledgments}

This research work was supported by the National Natural Science Foundation of China (Grant nos. 51878529 and 51678465) and the Research Project of Study on Key Technology of Large-Diameter Shield Tunnel Construction in biogas-rich soft ground. The support is gratefully acknowledged.

\section{References}

[1] G. Chen, H. Zhuang, and G. Shi, "Analysis on the earthquake response of subway station based on the substructure subtraction method," Journal of Disaster Prevention and Mitigation Engineering, vol. 24, no. 4, pp. 396-401, 2004.

[2] M. Singh, M. N. Viladkar, and N. K. Samadhiya, "Seismic analysis of Delhi metro underground tunnels," Indian Geotechnical Journal, vol. 47, no. 1, pp. 67-83, 2017.

[3] D. Ulgen, S. Saglam, and M. Y. Ozkan, "Dynamic response of a flexible rectangular underground structure in sand: centrifuge modeling," Bulletin of Earthquake Engineering, vol. 13, no. 9, pp. 2547-2566, 2015.

[4] V. W. Lee and M. D. Trifunac, "Response of tunnels to incident," SH-waves-Journal of the Engineering Mechanics Division, vol. 105, no. 4, pp. 643-659, 1979.

[5] W. Bourouaiah, S. Khalfallah, and S. Boudaa, "Influence of the soil properties on the seismic response of structures,"
International Journal of Advanced Structural Engineering, vol. 11, no. 3, pp. 309-319, 2019.

[6] I. Anastasopoulos, N. Gerolymos, V. Drosos, R. Kourkoulis, T. Georgarakos, and G. Gazetas, "Nonlinear response of deep immersed tunnel to strong seismic shaking," Journal of Geotechnical and Geoenvironmental Engineering, vol. 133, no. 9, pp. 1067-1090, 2007.

[7] K. Pitilakis and G. Tsinidis, Performance and Seismic Design of Underground Structures-Earthquake Geotechnical Engineering Design, pp. 279-340, Springer International Publishing, Cham, Switzerland, 2014.

[8] K. Pitilakis, G. Tsinidis, and A. M. Leanza, "Seismic behaviour of circular tunnels accounting for above ground structures interaction effects," Soil Dynamics and Earthquake Engineering, vol. 67, pp. 1-15, 2014.

[9] A. Maugeri, R. Mikaeil, and S. S. Haghshenas, "Integration of finite difference method and genetic algorithm to seismic analysis of circular shallow tunnels (case study: Tabriz urban railway tunnels)," KSCE Journal of Civil Engineering, vol. 22, no. 5, pp. 1-13, 2017.

[10] K. Wen, H. Shimada, T. Sasaoka et al., "Numerical study of plastic response of urban underground rock tunnel subjected to earthquake," International Journal of Geo-Engineering, vol. 8, no. 1, pp. 1-15, 2017.

[11] D. Park, M. Sagong, D. Y. Kwak et al., "Simulation of tunnel response under spatially varying ground motion," Soil $D y$ namics and Earthquake Engineering, vol. 29, no. 11-12, pp. 1417-1424, 2009.

[12] J. Chen, X. Shi, and J. Li, "Shaking table test of utility tunnel under non-uniform earthquake wave excitation," Soil Dynamics and Earthquake Engineering, vol. 30, no. 11, pp. 1400-1416, 2010.

[13] U. Cilingir and S. P. Gopal Madabhushi, "A model study on the effects of input motion on the seismic behaviour of tunnels," Soil Dynamics and Earthquake Engineering, vol. 31, no. 3, pp. 452-462, 2011.

[14] U. Cilingir and S. P. G. Madabhushi, "Effect of depth on the seismic response of square tunnels," Soils and Foundations, vol. 51, no. 3, pp. 449-457, 2011.

[15] M. R. Moghadam and M. H. Baziar, "Seismic ground motion amplification pattern induced by a subway tunnel: shaking table testing and numerical simulation," Soil Dynamics and Earthquake Engineering, vol. 83, pp. 81-97, 2016.

[16] Y. M. A. Hashash, J. J. Hook, and B. J. Schmidt, "Seismic design and analysis of underground structures," Tunnelling and Underground Space Technology, vol. 16, no. 4, pp. 247293, 2001

[17] G. Abate and M. R. Massimino, "Parametric analysis of the seismic response of coupled tunnel-soil-aboveground building systems by numerical modelling," Bulletin of Earthquake Engineering, vol. 15, no. 1, pp. 443-467, 2017.

[18] G. Tsinidis, E. Rovithis, and K. J. L. Pitilakis, "Seismic response of box-type tunnels in soft soil: experimental and numerical investigation," Tunnelling and Underground Space Technology, vol. 59, pp. 199-214, 2016.

[19] H. Chazelas, Z. Hu, X. Wang, and G. Chen, "Seismic responses of a large underground structure in liquefied soils by FEM numerical modelling," Bulletin of Earthquake Engineering, vol. 13, no. 12, pp. 3645-3668, 2015.

[20] ABAQUS, 6.12 Documentation, Dassault Systemes, Providence, RI, USA, 2014. 